\title{
Heat Transfer and Friction Factor Characteristics in Twisted Square Ducts
}

\author{
Madugula Udaya Kumar ${ }^{1, *}$, Mohmmad Yousuf Ali ${ }^{2}$ \\ ${ }^{1}$ Department of Mechanical Engineering, Indur Institute of Engineering \& Technology, Siddipet, India \\ ${ }^{2}$ Department of Mechanical Engineering, Avanthi College of Engineering and Technology, Hyderabad, India
}

Email address:

iiet.uday@gmail.com (M. U. Kumar)

${ }^{*}$ Corresponding author

\section{To cite this article:}

Madugula Udaya Kumar, Mohmmad Yousuf Ali. Heat Transfer and Friction Factor Characteristics in Twisted Square Ducts. International Journal of Mechanical Engineering and Applications. Vol. 6, No. 5, 2018, pp. 134-141. doi: 10.11648/j.ijmea.20180605.11

Received: October 13, 2018; Accepted: November 18, 2018; Published: December 24, 2018

\begin{abstract}
The present work experimental and numerical investigations have been carried out to study friction factor and heat transfer characteristics of twisted square ducts. Experiments were conducted for different velocities of air under constant heat flux condition, twist ratio is equal to 6.12 and also Reynolds number varied from 8000 to 30000 . The experimental analysis has been carried out and the experimentation is completely based upon design of experiments to get the optimum heat transfer rate and minimize pressure drop. The results of friction factor, Nusselt number and thermal performance factor are presented. Twisted square duct shows relatively higher heat transfer and optimum pressure drop compared to plain square duct. The experimental results shows that Nusselt number for the twisted square duct is about 1.89 times above that for the plain square duct while friction factor is 2.29 times higher $(\mathrm{f} / \mathrm{fo}=2.29)$. Thermal performance (enhancement ratio) of the twisted square duct is 1.41. In this work Numeric simulations were calculated by using the CFD software package ANSYS 18.2 FLUENT has been used. Heat transfer and numerical flow behaviors such as temperature, friction factor contours of the are also reported. Hence it is concluded that square duct with twist ratio 6.12 gives highest heat transfer and thermal performance due to lowest friction loss indicating promising device of the twisted square duct.
\end{abstract}

Keywords: Heat Transfer, Twisted Square Duct, Reynolds Number, Friction Factor, Twist Ratio, Enhancement, CFD Analysis

\section{Introduction}

Non circular cross section of ducts are extensively used in many heat exchangers.. Generally, design of any industrial process plants is influenced by need for optimum utilization of energy as effective usage of heat for economic design and operation. The need for effective utilization and recovery of heat has been prompted the development of various heat transfer enhancement techniques for heat exchangers. Augmentation techniques increase convective heat transfer by reducing thermal resistance in heat exchanger.

Amar RajSingh Suri [1] studied heat transfer and fluid flow behaviors of multiple square perforated twisted tapes in heat exchanger. The experimental investigations are carried out at twist ratio of 2.5 , Reynolds number varied from 5000 to 27000 . Nusselt number and friction factors are observed to be 6.96 and 8.34 times more than plain circular tube.

Experimentally and numerically investigations analysis has carriedout for three twisted square ducts with uniform cross section, divergent cross section and convergent cross section along the duct length. Twisted ratio used is 42 . Experiments were conducted using air as working fluid under constant wall heat flux boundary conditions with Re range of $10,000-100,000$. Thermal performance is compared with respect to straight square duct under constraints of identical mass flow rate, pumping power and pressure drop. It was concluded that for range of parameter studied divergent duct always enhance heat transfer, convergent duct always deteriorate heat transfer and straight duct may enhance or deteriorate performance depending upon comparison conditions.

Pressure drop and heat transfer behaviors of tube integral with commonly spaced quadruple twisted tape elements 
under turbulent flow regime have been investigated. Experiments were performed at twist ratio is equal to 2.5, constant heat flux conditions. Over the range reported, regularly spaced quadruple twisted tapes gives maximum thermal enhancement factor of $1.27[2,3]$

S. Eiamsa-ard and W. Changcharoen [4] reported that, influence of dual/quadruple twisted tapes in a square duct. Numerical simulations, flow structure, thermo hydraulic characteristics have been observed with different configurations. The analysis involves using the RNG $k-\varepsilon$ turbulent model under uniform wall heat flux condition for the Reynolds number ranging from 6000 to 14000 . The prediction indicates that thermo hydraulic characteristics in ducts with twisted tape are strongly dependent on number and configuration of tapes. As tape number increases, friction factor and heat transfer also increased. S. Ray and $M$. Khoshvaght et.al [5] studied spirally-coiled twisted-duct is used and also analyzed by both experimentally and numerically. The working fluids are water, nanofluid. The maximum improvement of Nusselt number and friction factor are noted for the spirally-coiled twisted-ducts with the lowest twist-pitch ratio is equal to 0.05 and coil-pitch is equal to 0.015 . Maximum performance values are 1.88 and 1.33 are recorded for nanofluid and water. K. Nanan et.al [6] have conducted an experiment for determining heat transfer enhancement by inserting helically twisted tapes, to induce co- and counter-swirl flows, The experiments were performed for fully developed turbulent flow with Reynolds number range between 6000 and 20,000, under uniform wall heat flux condition. nusselt number and friction factor increase with decreasing pitch ratio, while thermal performance factor possesses opposite trend. Effect of heat transfer in multi channel twisted tapes, under uniform flux condition, Reynolds number varied between 800 to 15000 . It was observed that maximum thermal performance factor of 1.04 at the lowest Reynolds number of 5000. pentagonal ribs are placed on bottom heated wall of a rectangular channel. Experiments are conducted for the determination of friction factor and heat transfer enhancement at various Reynolds numbers varying from 9400 to 58850 , pitch to height ratio six to twelve, Chamfering angle 0 to 20 degrees. For the low heat transfer zones in leeward vicinity of the square rib, Pentagonal ribs shows a significant improvement, specially prominent at higher Reynolds number,[7.8]

Natthaporn Kaewchoothong et.al [9] have observed that the effect of ribs in a stationary channel. They have investigated various types of ribs such as v shaped, inclined, inverted v shaped at constant Reynolds number 30000. The results given that the average Nusselt number on surface with rib inclined angle at $60^{\circ}, 45^{\circ}$ and $60^{\circ} \mathrm{V}$-shaped ribs was increased up to about $20 \%, 25 \%$ and $30 \%$ M. Hameed et.al [10] have studied the effect of triangular copper fins in a heat exchanger. The effectiveness became double by using twisted inserts with triangular copper fins.

PongjetPromvonge et.al [11] studied that an experimental research on thermal performance improvement in a constant heat-fluxed square ducts built-in winglet vortex generators and twisted tapes. The inserted duct at blockage ratio $=0.2$, pitch ratio $=2$ and twist ratio $=4$ provides the highest heat transfer rate and friction factor but the one at blockage ratio $=$ 0.1 , pitch ratio $=2$ and twist ratio $=4$ yields the highest thermal performance. The application of combined vortexflow devices gives thermal performance around 17\% higher than the twisted tape alone.

Friction factor and heat transfer characteristics of air flow inside twisted square duct under uniform wall temperature conditions with twist ratio of 11.5 and 16.5, Reynolds number varied from 600-70000. The results show significant improvement in pressure drop and heat transfer in laminar and turbulent flow regimes till Reynolds number of 9500 . Twist ratio of 11.5 shows quite higher pressure drop and heat transfer compared to plain square duct. Heat transfer and turbulent flow characteristics through twisted square duct have been numerically investigated. The working fluid is considered as water and the Reynolds number range between 10000 to 1200000 . The governing equations implied using the commercial code FLUENT. It has been observed that Twisted square duct provides significant increase in terms of Nusselt number to $138 \%$ over the plain square duct and utmost gain of 1.3 on thermal performance factor is obtained for the case of Reynolds number 10000. This represents the s00econdary flow occurred through the twisted square duct can increase the heat transfer rate. The edge size of square cross-section, the twist angle and the length of the channel are taken $0.01 \mathrm{~m}, 360^{\circ}$ and $0.2 \mathrm{~m}$, respectively.[12.13]

\section{Experimental Setup and Methodology}

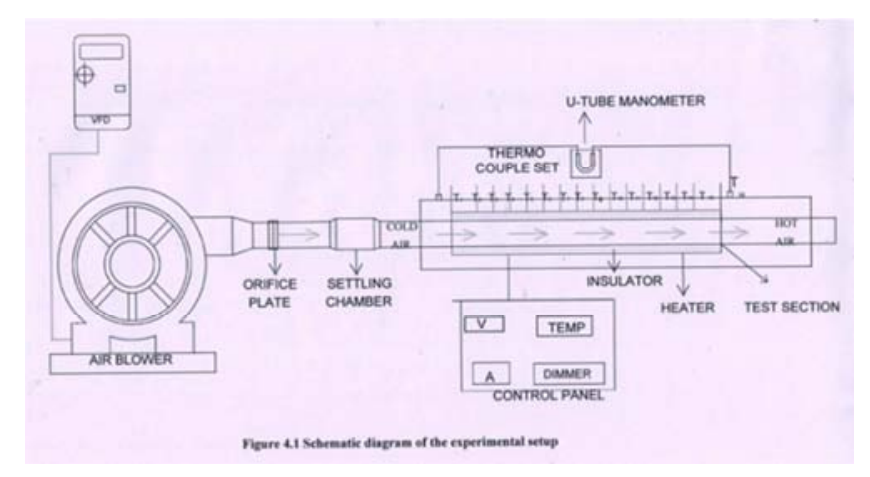

Figure 1. Schematic layout of Experimental setup.

\subsection{Method}

An experimental setup has been designed and fabricated to study heat transfer and friction factor characteristics of air under laminar and turbulent flow conditions in the twisted square duct. It is made of Aluminum material of length 1.5 $\mathrm{m}$, has a cross section of $65 \times 65 \mathrm{~mm}$, twist ratio 6.12 , Suction system a $1 \mathrm{~kW}$ blower was used to receive the air from the room to the test section. The test section was electrically heated by nichrome heater wire giving uniform wall heat flux boundary condition. The duct is controlled by a variac transformer to supply controllable electrical heating to the test duct. In order to maintain isothermal heating condition 
and with high accuracy, wall temperature distributions were measured over the heated part with 14 thermocouples with $0.1^{\circ} \mathrm{C}$ resolution. To control heat losses, wooden bars with low thermal conductivity, were placed around the tested square duct. The outer surface of the test duct was well insulated to lessen All thermocouples are type $\mathrm{K}$ and diameter of the wire is $1.5 \mathrm{~mm}$..

After ensuring steady state condition, record inlet, outlet and surface temperature readings velocity flow of air, mass flow of air, pressure difference at constant heat flux conditions. Based on these readings calculate Reynolds number, Nusselt number, Heat transfer coefficient, results of the twisted square duct have been investigated.

\subsection{Interpretation}

The present experiment was conducted to investigate the heat transfer augmentation in a Twisted square duct with twist ratio 6.12. primarily experimental results of heat transfer and friction factor characteristics in a square duct analyzed in terms of Nusselt number and friction factor.

The results obtained are displayed in dimensionless terms of Nusselt number and friction factor. The heat transfer coefficients are calculated by using the experimental data through the following equations:

$$
\begin{gathered}
\mathrm{h}=\mathrm{Q} / \mathrm{A}\left(\mathrm{T}_{\mathrm{s}}-\mathrm{T}_{\mathrm{b}}\right) \\
\mathrm{Q}=\mathrm{m} \cdot \mathrm{c}_{\mathrm{p}}\left(\mathrm{T}_{\mathrm{o}}-\mathrm{T}_{\mathrm{i}}\right) \\
\mathrm{m}=\rho \mathrm{AV} \\
\mathrm{N}=\mathrm{hD}_{\mathrm{h}} / \mathrm{k} \\
\mathrm{Re}=\mathrm{UD}_{\mathrm{h}} / \nu \\
\mathrm{f}_{\mathrm{e}}=\frac{\Delta \mathrm{p} * \mathrm{De}}{2 * \mathrm{~L} * \rho_{\mathrm{a}} * \mathrm{~V}^{2}}
\end{gathered}
$$

\subsection{Specifications and Boundary Conditions}

Length of the twisted square duct :1500 mm Width : $65 \mathrm{~mm}$

Height : $65 \mathrm{~mm}$

Thickness : $2 \mathrm{~mm}$

Twist angle : $270^{\circ}$

Table 1. Air Properties.

\begin{tabular}{lll}
\hline Properties at 1atmp & Fluid (Air) & Material (Aluminum) \\
\hline Density $\left(\mathrm{kg} / \mathrm{m}^{3}\right)$ & 1.156 & 2670 \\
Specific heat $(\mathrm{kg} / \mathrm{k})$ & 1005 & 860 \\
Thermal conductivity $(\mathrm{W} / \mathrm{mK})$ & 0.027 & 140 \\
Prandtl number & 0.7 & \\
Kinematic viscosity $\left(\mathrm{m}^{2} / \mathrm{sec}\right)$ & $16.5 \times 10-{ }^{6}$ & \\
\hline
\end{tabular}

Table 2. Boundary conditions.

\begin{tabular}{ll}
\hline NAME & TYPE \\
\hline Inlet & Velocity \\
Outlet & Pressure \\
Right wall & Heat Flux \\
Left wall & Heat Flux \\
Sidewalls & Heat Flux \\
\hline
\end{tabular}

\subsection{Nomenclature}

A- Convection heat transfer area of duct, $\mathrm{m}^{2}$ AR-Aspect ratio of duct, $(\mathrm{W} / \mathrm{H})$

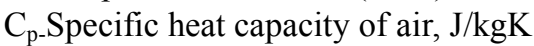
$\mathrm{D}_{\mathrm{h}}$-Hydraulic diameter of duct, $(=\mathrm{H}), \mathrm{m}$ Fo-Friction factor for plain duct f-Friction factor for twisted square duct $\mathrm{H}$-Duct height, $\mathrm{m}$

h-Heat transfer coefficient, $\mathrm{W} / \mathrm{m}^{2} \mathrm{~K}$

I- Current, A

$\mathrm{k}$-Thermal conductivity of air, $\mathrm{W} / \mathrm{mK}$

$\mathrm{L}$-Length of test duct, $\mathrm{m}$ $\mathrm{m}$-Mass flow rate of air, $\mathrm{kg} / \mathrm{s}$

Nuo-Nusselt number of plain duct,

$\mathrm{Nu}-\mathrm{Nusselt}$ number of Twisted square duct Pr-Prandtl number

Re- Reynolds number, (UD/v) (dimensionless)

Q- Heat transfer, W

q-heat flux, W/m

$\mathrm{T}$ - Temperature, $\mathrm{K}$

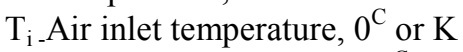

$\mathrm{T}_{\mathrm{o}}$ - Air outlet temperature, $0^{\mathrm{C}}$ or $\mathrm{K}$

$\mathrm{T}_{\mathrm{b}}$ Bulk temperature, $\left(\mathrm{T}_{\mathrm{i}}+\mathrm{T}_{\mathrm{o}}\right) / 2,0^{\mathrm{C}}$ or $\mathrm{K}$

$\mathrm{T}_{\mathrm{s}}$ Surface temperature, $0^{\mathrm{C}}$ or $\mathrm{K}$

$\mathrm{U}$ Mean velocity, $\mathrm{m} / \mathrm{s}$

V Voltage, V

W Width of the duct, $\mathrm{m}$ $\mathrm{y}$ Twist ratio, dimensionless ( $\mathrm{s} / \mathrm{D}), \mathrm{m}$

$\mathrm{S}$ Pitch of the twisted tube, $\mathrm{m}$

Greek letters

$\Theta$ Twist angle

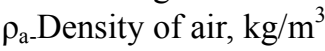

$\eta$ Thermal performance factor ( enhancement ratio) $\mu$ Dynamic viscosity, $\mathrm{kg} \mathrm{s}^{-1} \mathrm{~m}^{-1}$

$\mathrm{t}_{\mathrm{w}}$ twisted square duct

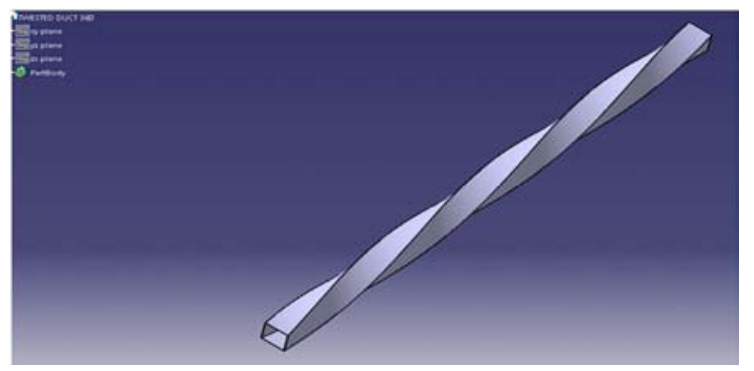

Figure 2. Twisted duct modeling.

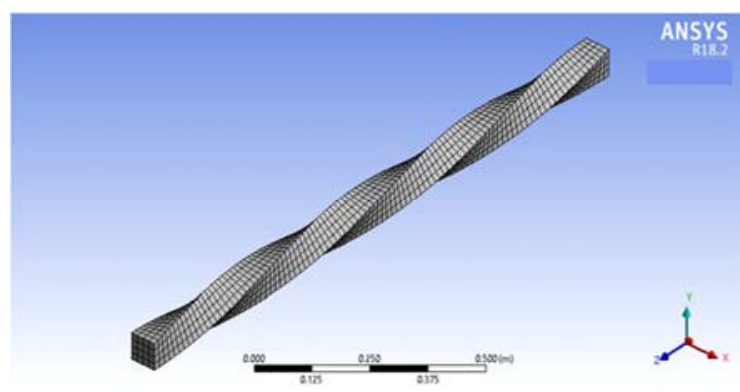

Figure 3. Twisted duct meshing. 


\section{Results and Discussions}

The experimental results of Nusselt number and friction factor of the present plain Square duct are compared with those from correlations of Dittus-Boelter, Blasius and Petukhov found for turbulent flow in ducts.

Correlation of Dittus-Boelter,

$$
\mathrm{Nu}=0: 023 \operatorname{Re}^{0: 8} \operatorname{Pr}^{0: 4} \text { for heating }
$$

Correlation of Petukhov,

$$
\mathrm{f}=0.79\left(\ln \mathrm{Re}^{-1: 64)^{-2}}\right.
$$

En Thermal performance ratio $=(\mathrm{Nu} / \mathrm{Nuo}) /(\mathrm{f} / \mathrm{fo})^{0.33}$

The comparison of Nusselt number and friction factor obtained from the present plain square duct with those from correlations of Equations (6), (7) are represented.

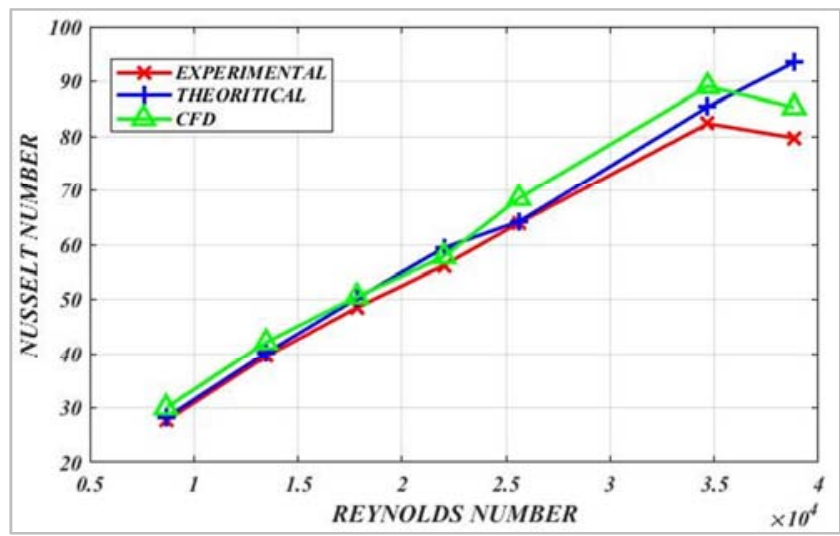

Figure 4. Data verification of Nusselt number versus Reynolds number for plain square duct.

The above graph presents variant of Nusselt number with Reynolds number for plain square duct using air as test fluid. The data obtained by the experiment for plain square duct (both $N u$ and Re defined on the basis of Hydraulic diameter) were compared with Dittus-Boelter equation. It is observed that the average deviation between the predicted and experimental values has been \pm 2.0 to $\pm 5 . \%$ for Nusselt number respectively. Thus the results obtained and the predicted values are in good agreement, which ensures the accuracy of the experimental data with the present experimental set-up. The increase of Nusselt number with rising Reynolds number is accountable by decline of thermal boundary layer thickness due to turbulent intensity.

The figure 5 reveals that variation of nusselt number with Reynolds number for twisted square duct. It is visible that experimental and computational values are with in the permissible limits i.e. $\pm 4.8 \%$. Therefore experimental setup is deemed to be validated under air is testing fluid. It is also explains from the above figure nusselt number is increases while Reynolds number is increased

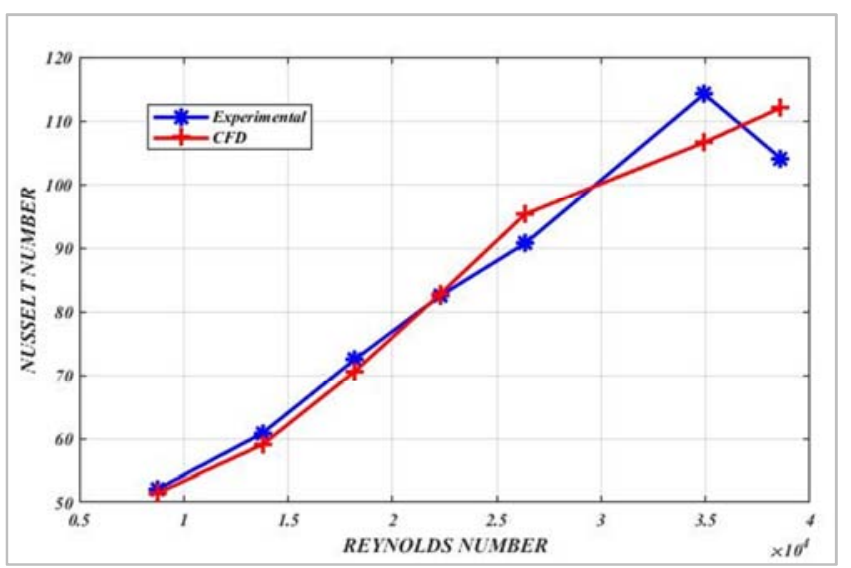

Figure 5. Comparison of Experimental and numerical results for Twisted square duct.

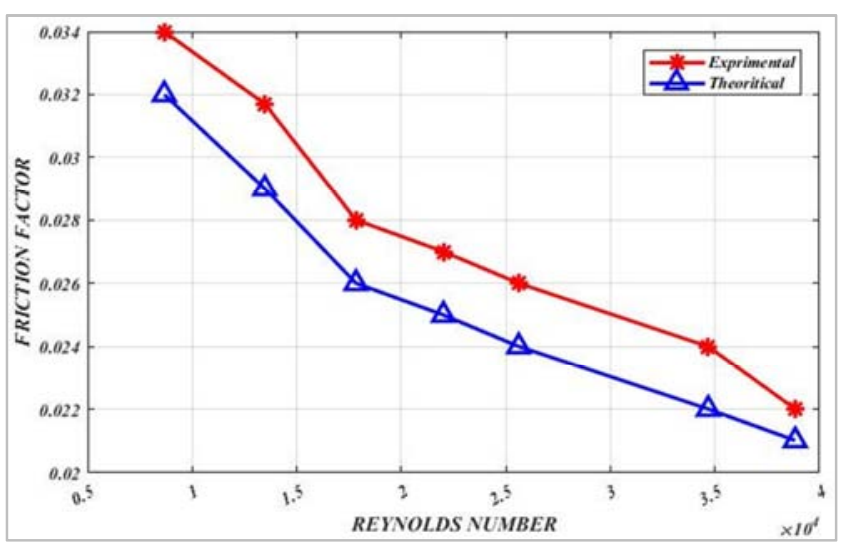

Figure 6. Variation of friction factor with Reynolds number for plain square duct.

The above graph represents the friction factor decreases along with Reynolds number increased. This is due to at higher velocity fluid molecules are randomly placed on the surface walls of the duct. It leads to increases pressure drop.

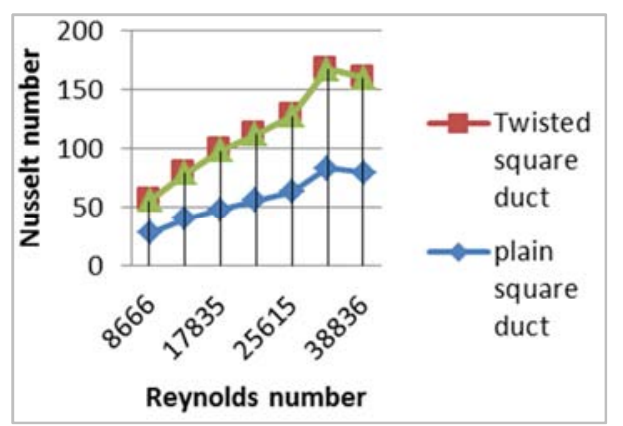

Figure 7. Comparison between plain and twisted square ducts.

The above graph represents nusselt number variation of the plain and twisted square duct along with Reynolds number. It is clearly notified twisted square duct has highest nussuelt number rather than plain square duct for the same operating conditions. This is due to twist ratio 6.12 gives proper mixing of fluid molecules and high turbulence is created. 


\section{CFD Analysis}

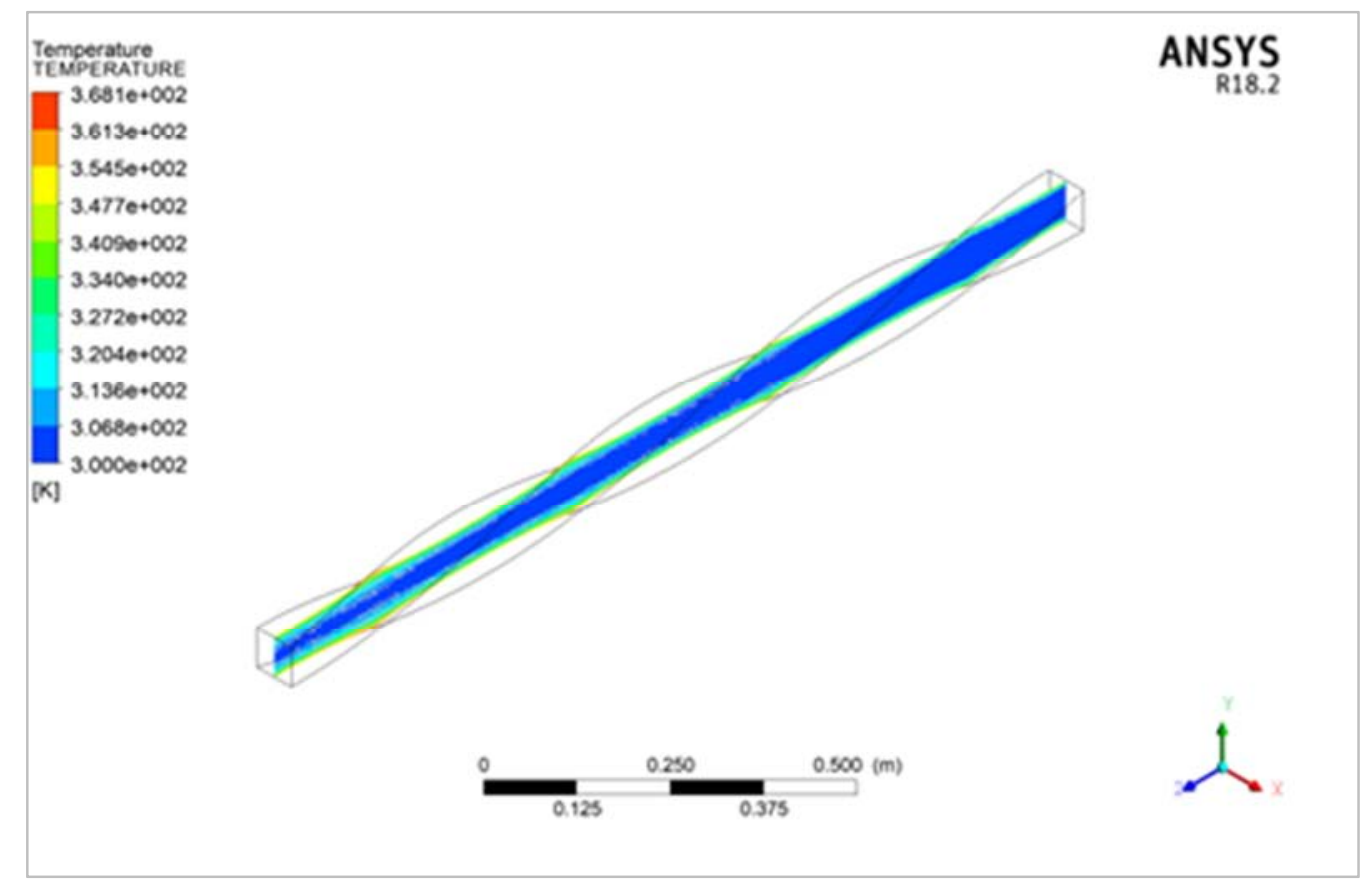

Figure 8. Temperature contour of twisted square duct at velocity of $2.2 \mathrm{~m} / \mathrm{sec}$.

The above diagram represents temperature distribution of twisted square duct at velocity $2.2 \mathrm{~m} / \mathrm{sec}$. It is visible that temperature difference between inlet and outlet is maximum. This is due to required twist ratio and proper mixing of fluid molecules in the twisted duct.

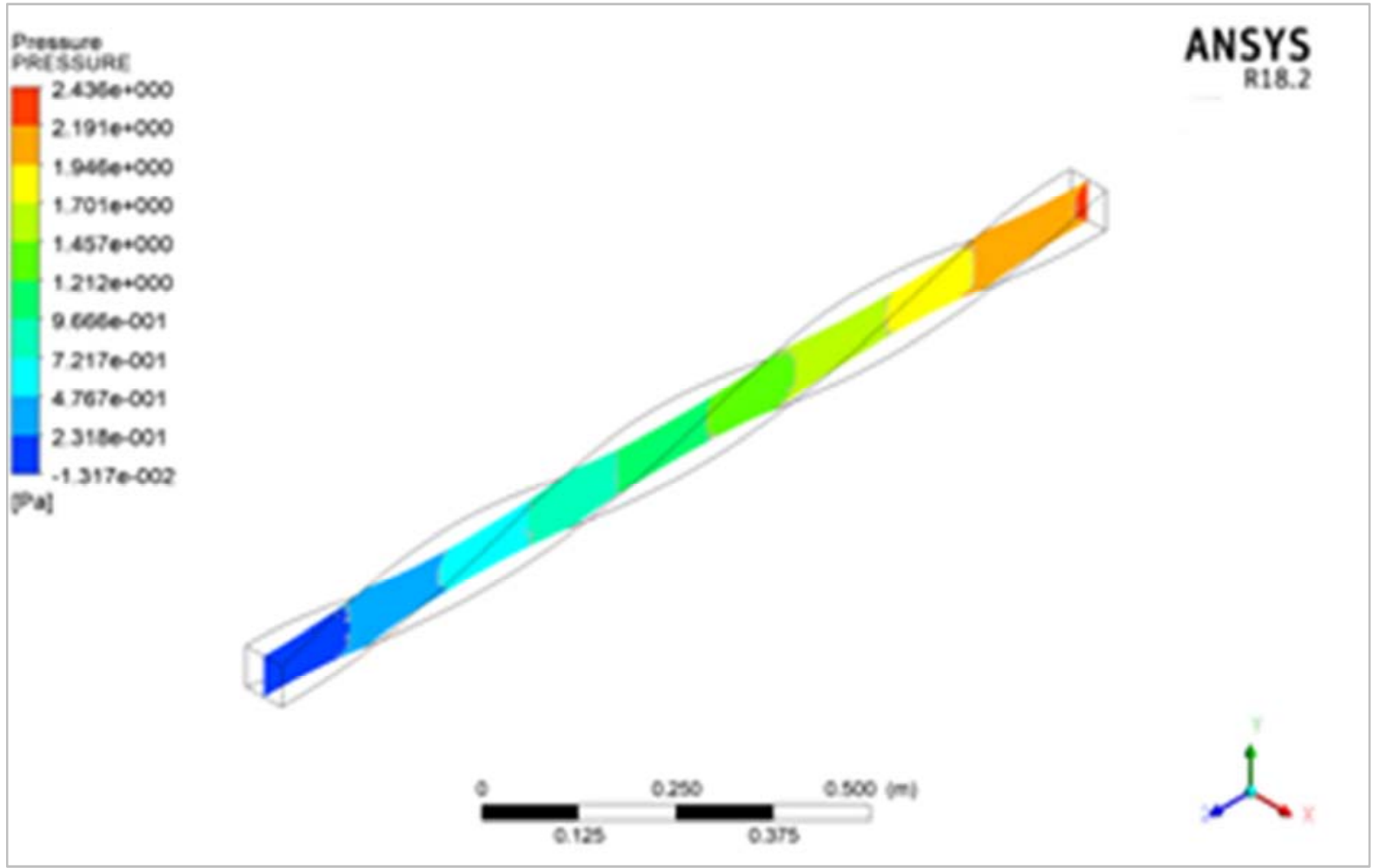

Figure 9. Pressure contour of twisted square duct at velocity of $2.2 \mathrm{~m} / \mathrm{sec}$.

The figure 9 observed that pressure variation in the twisted sqaure duct. It is clearly noticed that pressure drop is increased for twisted square duct rather than plain square duct due to twisted shape of duct 


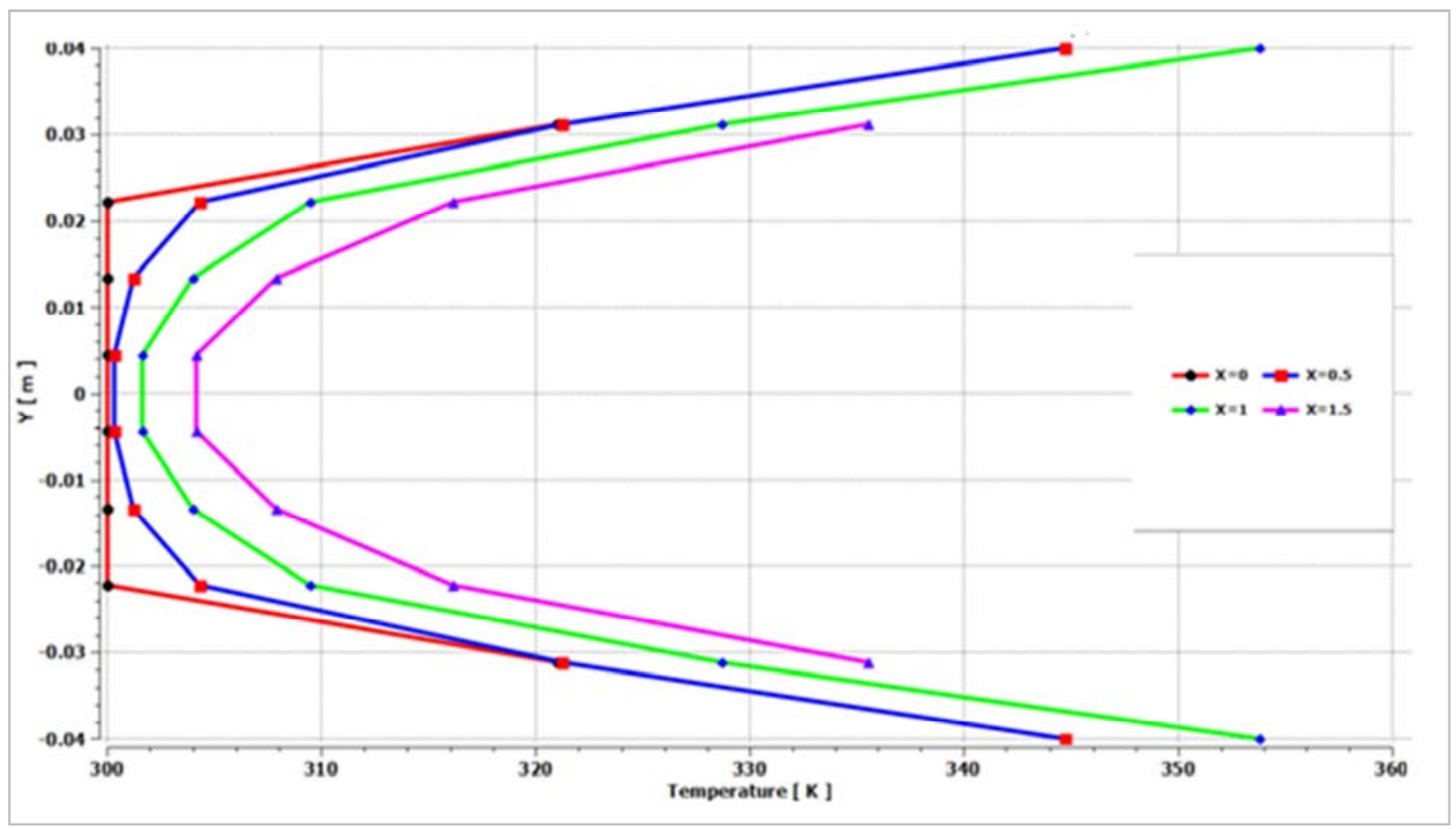

Figure 10. Temperature profile( verticaldirection) of Twisted sqaure duct at velocity of $2.2 \mathrm{~m} / \mathrm{sec}$.

The figure 10 represented that the variation of air flow in the plain square duct at velocity $2.2 \mathrm{~m} / \mathrm{sec}$ at different intervals of the whole length of the duct. It has been observed that at $Y=0.025$ the velocity becomes high due to there is no obstruction in the flow.

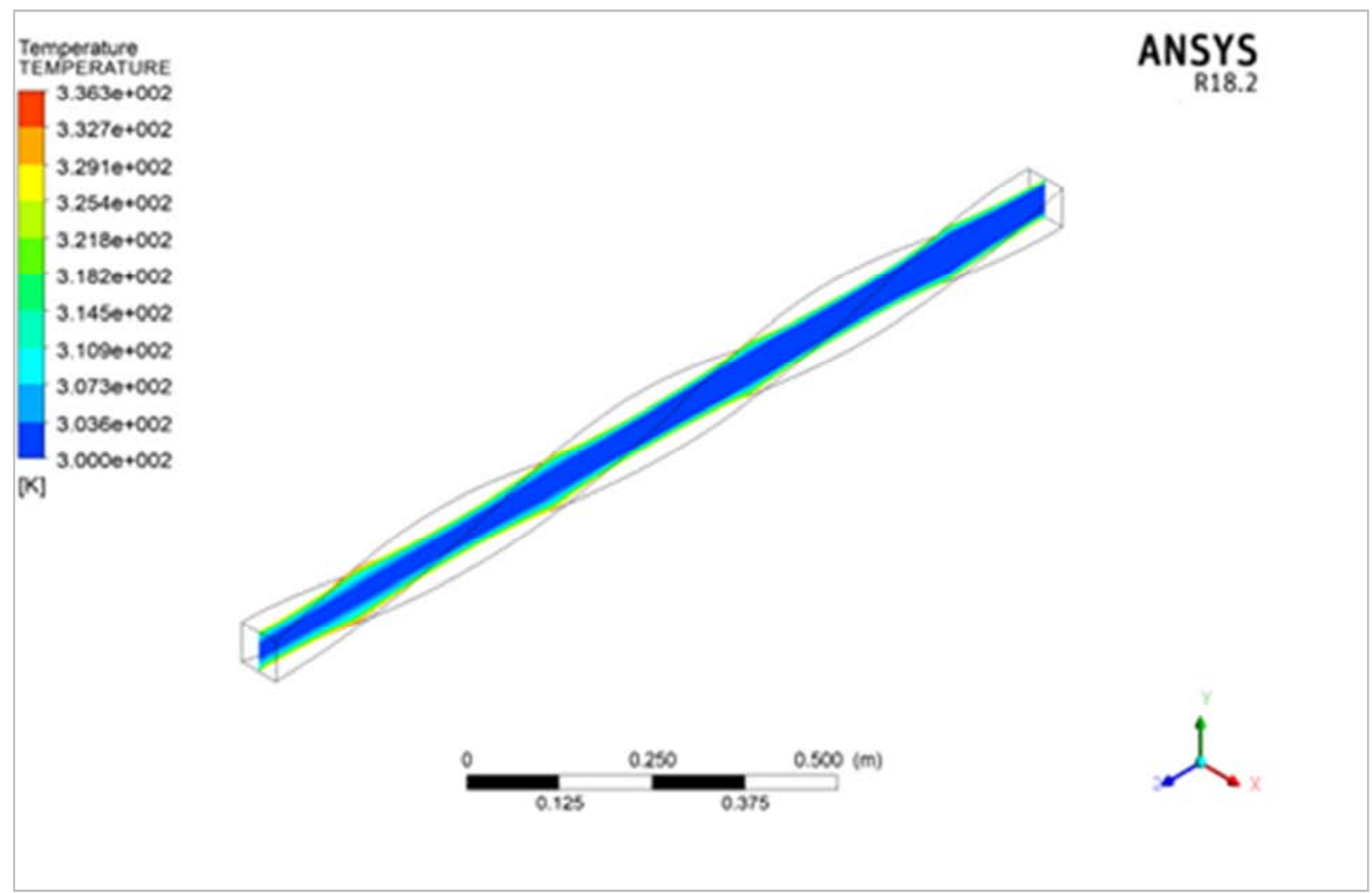

Figure 11. Temperature contour of twisted square duct at velocity of $4.5 \mathrm{~m} / \mathrm{sec}$.

The above figure represents temperature difference between outlet and inlet is gradually decreased at velocity of $4.5 \mathrm{~m} / \mathrm{sec}$. This is due to fluid particles placed in zigzag manner in the duct. 


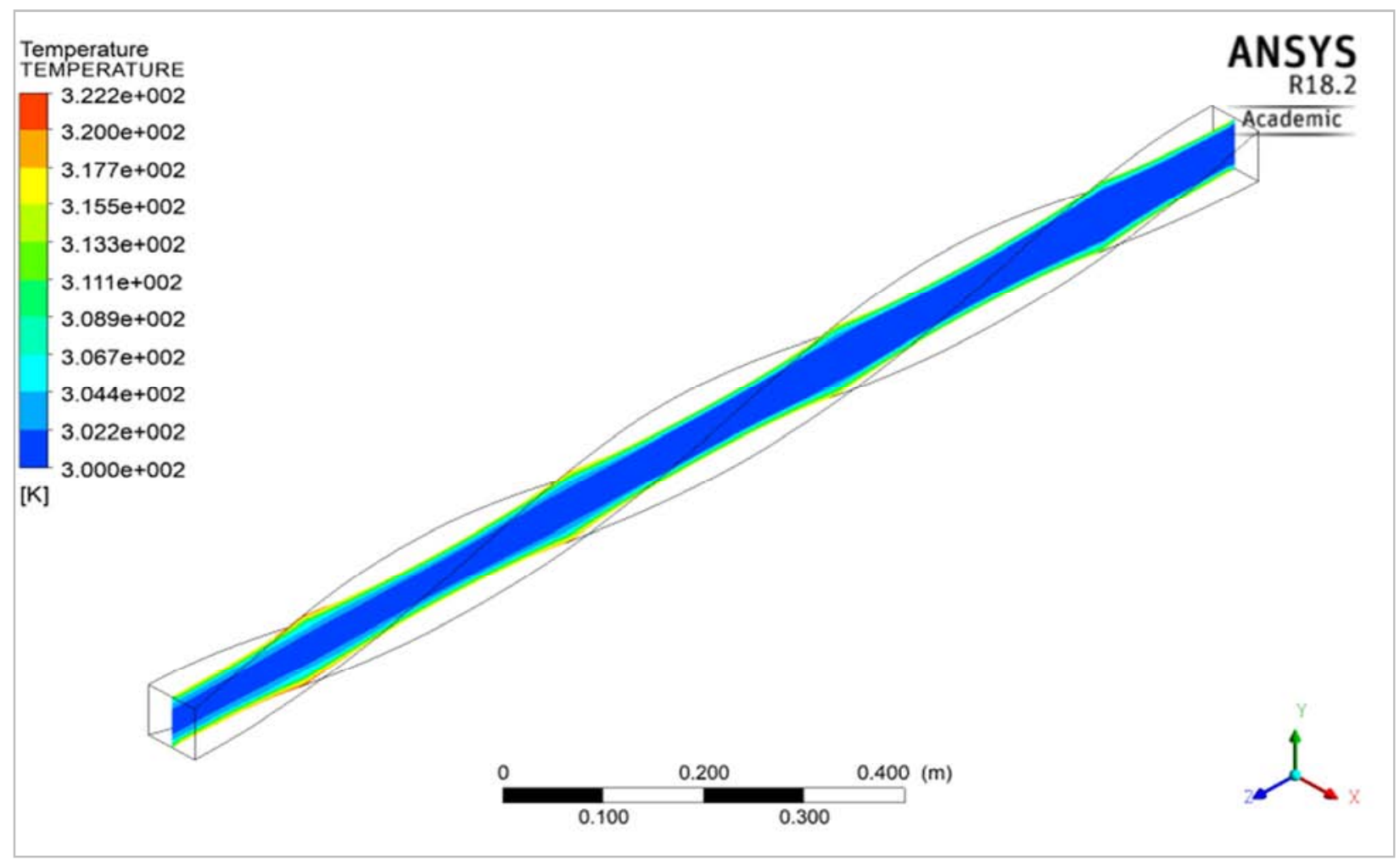

Figure 12. Temperature contour of twisted square duct at velocity of 8.6 m.sec.

\section{Conclusions}

Following main conclusions are drawn from these investigations

The heat transfer coefficient increased with Reynolds number increases in twisted square duct and Te highest heat transfer coefficient is obtained at velocity of air flow is equal to $8.6 \mathrm{~m} / \mathrm{sec}$. This is due to higher swirling flow or turbulence, long residence time in the duct

The experimental Nusselt number for twisted square duct is maximum at velocity $8.6 \mathrm{~m} / \mathrm{sec}$ i.e. 114.2 under constant heat flux condition with air as test fluid.

The experimental results shows that twisted duct $(\mathrm{Nu} / \mathrm{Nuo}=1.89)$ i.e. Nusselt number for the twisted square duct is about 1.89 times above that for the plain square duct while friction factor is 2.29 times higher $(\mathrm{f} / \mathrm{fo}=2.29)$.

Thermal performance (enhancement ratio) of the twisted square duct is 1.41

Finally it is concluded that Twisted square duct perform better heat transfer enhancement than plain square duct.

\section{References}

[1] Amar RajSingh Suri, Anilkumar, Rajesh Maithani "Heat transfer enhancement of heat exchanger tube with multiple square perforated twisted tape inserts" Experimental investigation and correlation development, Chemical Engineering processing process Intensification Volume 116 (2017)Pages 76-96.

[2] Liang-Bi Wang1 Wen-Quan Tao Qiu-Wang Wang Ya-Ling He "Experimental and Numerical Study of Turbulent Heat
Transfer in Twisted Square Ducts"ASMEVol 123, (2001) 868877.

[3] P. Samruaisin, W. Changcharoen, c. Thianpong, V. Chuwattanakul, M. Pimsarn, S. Eiamsa-ard "Influence of regularly spaced quadruple twisted tape elements on thermal enhancement characteristics" Chemical Engineering and Processing Intensification, Volume 128(2018) pp 114-123.

[4] S. Eiamsa-ard , W. Changcharoen“" Flow structure and heat transfer in a square duct fitted with dual/quadruple twistedtapes: Influence of tape configuration "Journal of Mechanical Science and Technology29(2015) 3501-3518.

[5] M. Khoshvaght Aliabad S. F. Khaligh Z. Tavassoli,"An investigation of heat transfer in heat exchange devices with spirally-coiled twisted-ducts using nanofluid," Applied Thermal Engineering, Volume 143(2018) pp, 358-375.

[6] K. NananK. YongsiriK. Wongcharee, C. Thianpong, S. Eiamsa-ard" "Heat transfer enhancement by helically twisted tapes inducing co- and counter-swirl flows" 46(2013) 67-73.

[7] A Saysroy , S. Eiamsa-ard "Enhancing convective heat transfer in laminar and turbulent flow regions using multichannel twisted tape inserts" International Journal of Thermal sciences, volume 121, pp55-74.

[8] Naveen Sharma, Andallib, TandallibTariq, Manish Mishra, "Experimental Investigation of Heat Transfer Enhancement in Rectangular Duct with truncated Pentagonal Ribs", Journal Heat transfer Engineering, 2018, pp 383-396.

[9] Natthaporn Kaewchoothong, Kittinan Maliwan , Kenichiro Takeishi , Chayut Nuntadusit "Effect of inclined ribs on heat transfer coefficient in stationary square Channel" Theoretical \& Applied Mechanics Letters 7 (2017), pp 344-350. 
[10] Vinous M. Hameed, Maha A . Hussein "Effect of new type of enhancement on inside and outside surface of the tube side in single pass heat exchanger" Applied Thermal Engineering, Volume 122 (2017), pp484-491.

[11] Pongjet Promvonge, Supattarachai Suwannapan, Monsak Pimsarn, Chinaruk Thianpong "Experimental study on heat transfer in square duct with combined twisted-tape and winglet vortex generators" (ICHMT 2015) 59( 2014) 158165 .
[12] R Bhadouriya, A Agrawal, SV Prabhu "Experimental and numerical study of fluid flow and heat transfer in a twisted square duct" Journal of Heat and Mass Transfer, 82( 2015) $143-158$.

[13] Nihal UĞURLUBİLEK "Numerical investigation of heat transfer and flow in a twisted shaped square duct" Journal . of Thermal Science and Technology , 32(2012), 121-131. 